\title{
Development and validation of enantiomeric purity of Montelukast by SFC method on amylose based stationary phase
}

\author{
Vijaya Lakshmi.Maddala*, Kameswararao.Ch, Srinivasulu.Polisetty, \\ Sai Venkata Srinivas Koduri, P.C.Ray \\ Inogent laboratories Pvt Ltd, IDA-Nacharam, Hyderabad. \\ Jawaharlal Nehru Technological University Hyderabad, India \\ ${ }^{*}$ Corresponding author: Vijayalakshmi.M \\ E mail:Vijaya_chem@yahoo.com
}

\begin{abstract}
:
A new Supercritical fluid liquid chromatographic (SFC) method has been developed in normal-phase conditions for the determination of enantiomeric purity of Montelukast sodium (S,E)-2-(1-((1-3-(2-(7-chloroquinolin-2-yl)vinyl)phenyl)-3-(2-(2hydroxypropan-2-yl)phenyl)propylthio)ethyl) cyclopropyl) acetic acid (R-isomer) (Anti asthmatic drug) in bulk drugs and in dosage forms. The sample was screened on the analytical SFC to determine the best column for the separation. The screening conditions are Column: Chiralpak AS-H $(250 \mathrm{~mm} \times 4.6 \mathrm{~mm}, 5 \mu \mathrm{m})$ column using a mobile phase system containing Supercritical fluid $\left(\mathrm{CO}_{2}\right)$ and 2-Propanol in the ratio $(85: 15 \% \mathrm{v} / \mathrm{v})$. The mobile-phase compositions and the differences in separation capability of the method is noted. The resolution between two enantiomers is found to be greater than 1.5. The SFC method for the separation of enantiomers of Montelukast is proved Accurate, Precise, Linear and robust. Relative standard deviation of retention times and peak areas were better than $0.2 \%$ and $0.4 \%$, respectively, for precision.
\end{abstract}

\section{Council for Innovative Research}

Peer Review Research Publishing System

\section{Journal: Journal of Advances in Chemistry}

\author{
Vol. 4, No. 3 \\ editor@cirworld.com \\ www.cirworld.com, member.cirworld.com
}




\section{Introduction}

Montelukast sodium is primarily used for the treatment of asthma in children and adults. It is a potent selective inhibitor of leukotriene D4 (LTD4) at the cysteinyl leukotriene receptor cysLT1. This compound is one of the most significant advances in asthma therapy in the last 25 years and is commonly used for the treatment of nocturnal asthma. Literature survey reveals that chiral liquid chromatographic method is for the separation of enantiomeric purity for Montelukast sodium and its S-enantiomer. The present study illustrates development and validation of a simple, accurate and precise procedure for determination of s-enantiomer of montelukast sodium by SFC method in bulk and in tablet dosage form. It can be applied for preparative SFC separation method for resolving the enantiomers of Montelukast. Chromatographic separations of enantiomers have attracted wide attention since the important difference in biological activity of enantiomers became recognized. In this paper SFC was chosen because of solvent saving relative to conventional HPLC.

The objective of the present investigation is to develop and validate a simple, reliable, and Supercritical fluid liquid chromatographic method for the enantiomeric separation of Montelukast using an amylose-based CSP column. The mobile phase in normal phase mode is simple to prepare and the method is rugged in any environment and comfort in use.

\section{Experimental}

\section{Chemicals and reagents}

Montelukast racemic mixture $( \pm$ ) was obtained from the R\&D department of Inogent laboratories (Hyderabad, India). Chemical structure is presented in Figure 1. HPLC-grade 2-Propanol and Methanol were purchased from Merck (Mumbai, India). All other chemicals were of analytical-grade, Carbon dioxide with high purity was supplied from MRG Enterprises Hyderabad, India. The analyte concentration of Montelukast was fixed as $1.0 \mathrm{mg} / \mathrm{mL}$. Working solutions of Montelukast were prepared in Methanol.

\section{Apparatus}

The SFC experiments were performed on a Thar SD-ASFC-2 system (Thar Technologies, Pittsburgh, PA) equipped with a Waters PDA detector. The system was controlled by Superchrom software. The enantiomeric separation was performed on a Chiralpak AS-H [Amylose tris (3,5-dimethylphenylcarbamate) coated on $5 \mu \mathrm{m}$ silica-gel), $250 \times 4.6 \mathrm{~mm}$ i.d., $5 \mu \mathrm{m}$ ]. The chromatography was conducted using $\mathrm{CO}_{2}$ composed with different types and percentages of alcohol modifiers as the mobile phase. For the separation experiments, the total flow rate of the mobile phase, the outlet backpressure, the injection volume, and the UV detection wavelength were fixed as at $2.5 \mathrm{~mL} / \mathrm{min}, 100$ bars, $20 \mu \mathrm{L}$, and $230 \mathrm{~nm}$, respectively. The oven temperature was set at $25^{\circ} \mathrm{C}$, to determine the effect of temperature on enantiomeric separation. The chromatographic parameters, including the retention factor $(k)$, the separation factor $(\alpha)$, and the resolution (Rs) were selected to evaluate the separation of the compounds. All the chromatographic results were repeated three times.

Different chiral columns were also employed during method development namely Chiralcel OD-H $(250 \times 4.6 \mathrm{~mm}, 5 \mu)$, Chiralpak IC $(250 \times 4.6 \mathrm{~mm}, 5 \mu)$,Amylose-2 $(250 \times 4.6 \mathrm{~mm}, 5 \mu)$, Chiralcel OJ-H $(250 \times 4.6 \mathrm{~mm}, 5 \mu)$, Chiralpak AS-H $(250 \times$ $4.6 \mathrm{~mm}, 5 \mu)$ and finally on Chiralpak AD-H $(250 \times 4.6 \mathrm{~mm}, 5 \mu)$.

\section{Validation of the method}

\section{Precision}

Precision was determined by measuring repeatability and reproducibility of retention times and peak areas of each enantiomer. In order to determine the repeatability of the method, six injections $(n=6)$ of standard was carried out from single preparation. The reproducibility of the method was determined by analyzing six different preparations of test solutions containing Montelukast $(1.0 \mathrm{mg} / \mathrm{mL})$.

\section{Linearity}

Linear response was determined by preparing and analyzing five calibration solutions of the enantiomers (concentration from $0.5 \mathrm{mg} / \mathrm{mL}$ to $2.0 \mathrm{mg} / \mathrm{mL}$ ) in methanol. Regression curve was obtained by plotting peak area versus concentration using the least squares method. Linearity was checked for three consecutive days in the same concentration range from the same stock solution. The percentage relative standard deviation of the slope and $Y$-intercept of the calibration curve were calculated.

\section{Robustness}

The robustness of a method is the ability of the method to remain unaffected by small changes in parameters such as flow rate, mobile phase composition, and column temperature. To determine robustness of the method experimental conditions were purposely altered and chromatographic resolution between (+) enantiomer and (-) enantiomer was evaluated. The flow rate of the mobile phase was $2.50 \mathrm{~mL} / \mathrm{min}$. To study the effect of flow rate on the resolution of enantiomers, 0.5 units $( \pm 20 \%)$ changed it from 2.0 to $3.0 \mathrm{~mL} / \mathrm{min}$. The effects of change in percent of Supercritical fluid Carbon dioxide, and 2-Propanol on resolution were studied by varying from $\mathrm{CO} 2$ to $+2 \%$ while the other mobile phase components were held constant as stated in the Apparatus section. 


\section{Results and Discussion}

\section{Optimization of chromatographic conditions}

Racemic mixture solution of Montelukast (10 $\mathrm{gg} / \mathrm{mL}$ each) is prepared in methanol for development. To develop a rugged and suitable SFC method for the separation of the two enantiomers, different stationary phases and mobile phases were employed. Initial screening of chiral column was carried out by several chiral LC column suppliers. Various chiral columns, namely Chiralcel OD-H $(250 \times 4.6 \mathrm{~mm}, 5 \mu)$, Chiralpak IC $(250 \times 4.6 \mathrm{~mm}, 5 \mu)$, Amylose-2 $(250 \times 4.6 \mathrm{~mm}, 5 \mu)$, Chiralcel OJ-H $(250 \times 4.6 \mathrm{~mm}, 5 \mu)$, Chiralpak AS-H $(250 \times 4.6 \mathrm{~mm}, 5 \mu)$, were employed. All these columns failed to provide selectivity between Montelukast peak and the undesired enantiomer peak using different possible mobile phases. Different method development trails are shown in Figure .Different method development trail conditions are tabulated in Table.1.

It was continued to select the best stationary and mobile phases that would give optimum resolution and selectivity for the two enantiomers. There was an indication of separation on Chiralpak AS-H $(250 \times 4.6 \mathrm{~mm}, 5 \mu \mathrm{m})$ column using a mobile phase consisting of Supercritical fluid liquid $\left(\mathrm{Co}_{2}\right)$, and 2-Propanol in the ratio 85:15. The composition of the mobile phase was optimized to enhance the chromatographic efficiency and resolution between the enantiomers. Based on the data obtained from method development and optimization activities, Chiralpak AS-H $(250 \times 4.6 \mathrm{~mm}, 5 \mu \mathrm{m})$ column with mobile phase of Supercritical fluid liquid $\left(\mathrm{Co}_{2}\right)$ and 2-Propanol $(85: 15 \%, \mathrm{v} / \mathrm{v})$ was selected for the final method. The flow rate of the final method was $2.5 \mathrm{~mL} / \mathrm{min}$ with an injection volume of $20 \mu \mathrm{L}$. The column temperature was $25^{\circ} \mathrm{C}$, and the detection wavelength was $230 \mathrm{~nm}$. Under these conditions, the two enantiomers were separated well and the peak of (S)enantiomer eluted after the peak of Montelukast. In the optimized method, the typical retention times of Montelukast and (s)-enantiomer were approximately Montelukast a total run time of $20 \mathrm{~min}$. The separation of an approximately 1:1 (wt/wt) mixture solution (in methanol) of the two enantiomers is shown in Figure. An amylose based chiral stationary phase contained five chiral centers per unit, and Montelukast had only one chiral center close to the thiopropyl methyl cyclopropane group in the structure. The stereoelectronic interactions between the enantiomers and the chiral stationary phase generated enantioselectivity, thus causing significant differences in the migration of the enantiomers inside the column. Having the right amount of methanol in the mobile phase also played an important role in affecting the steric environment of the chiral cavities or channels of the stationary phase and contribute to enantioselectivity. However, an excessive amount of methanol was likely to cut down the resolution by taking up chiral centers of the chiral stationary phase or forming hydrogen bondings with the enantiomers instead of the hydrogen bondings between the enantiomers and the stationary phase (14). Other important interactions between the enantiomers and the stationary phase such as $\pi " \mathrm{C} \pi$ bonding, Vander Waals forces, dipole induced dipole attractions, and steric effects can also achieve better resolution on Chiralpak AS-H column.

\section{Validation of method}

In the repeatability study, the relative standard deviation (RSD) was better than $0.2 \%$ for the retention times and $0.4 \%$ for peak areas of both the enantiomers. In reproducibility studies, results show that RSD values were in the same order of magnitude than those obtained for repeatability. Coefficient of correlation between concentration and detector response [0.999 for the first eluting (+) enantiomer and 0.999 for the second eluting ("C) enantiomer] shows that method is linear over the concentration range of $0.4^{\prime \prime} \mathrm{C} 1.2 \mathrm{mg} / \mathrm{mL}$. The limit of detection (LOD), determined as the amount for which the signal to- noise ratio was $\sim 3: 1$ for both enantiomers of Montelukast, was $0.05 \mathrm{mg} / \mathrm{mL}$.

The chromatographic resolution of Montelukast peaks were used to evaluate the method robustness under modified conditions. The resolution between $(+)$ enantiomer and (-) enantiomer was greater than 2.0 under all separation conditions tested, demonstrating sufficient robustness.

\section{Conclusions}

A simple, rapid, accurate and precise Supercritical fluid liquid chromatographic method for the enantiomeric separation of Montelukast has been developed and validated. Amylose based Chiralpak AS-H column was found to be suitable for the separation of the enantiomers of Montelukast. Use of Chiralpak AS-H column with Supercritical fluid liquid $\left(\mathrm{CO}_{2}\right)$ and $2-$ Propanol $(85: 15 \%, v / v)$ as mobile phase was most suitable for separation of the enantiomers of Montelukast. The analysis of enantiomeric separations by SFC is less time, cost effective and environmentally eco friendly than Normal phase liquid chromatographic Methods. This method is used for the isolation of un required isomer by using the preparative SFC system with less time and less cost. 
<smiles>CC(C)(O)c1ccccc1CC[C@H](SCC1(CC(=O)O)CC1)c1cccc([C@H](Cc2ccc3ccc(Cl)cc3n2)SCC2(CC(=O)O)CC2)c1</smiles><smiles>CC(C)(O)c1ccccc1CC[C@H](SCC1(CC(=O)O)CC1)c1cccc([C@@H](Cc2ccc3ccc(Cl)cc3n2)SCC2(CC(=O)O)CC2)c1</smiles>

Figure 1: Montelukast $\mathrm{R}$ isomer and S-Isomer

Chromatograms:

a) Montelukast spiked with S-isomer:

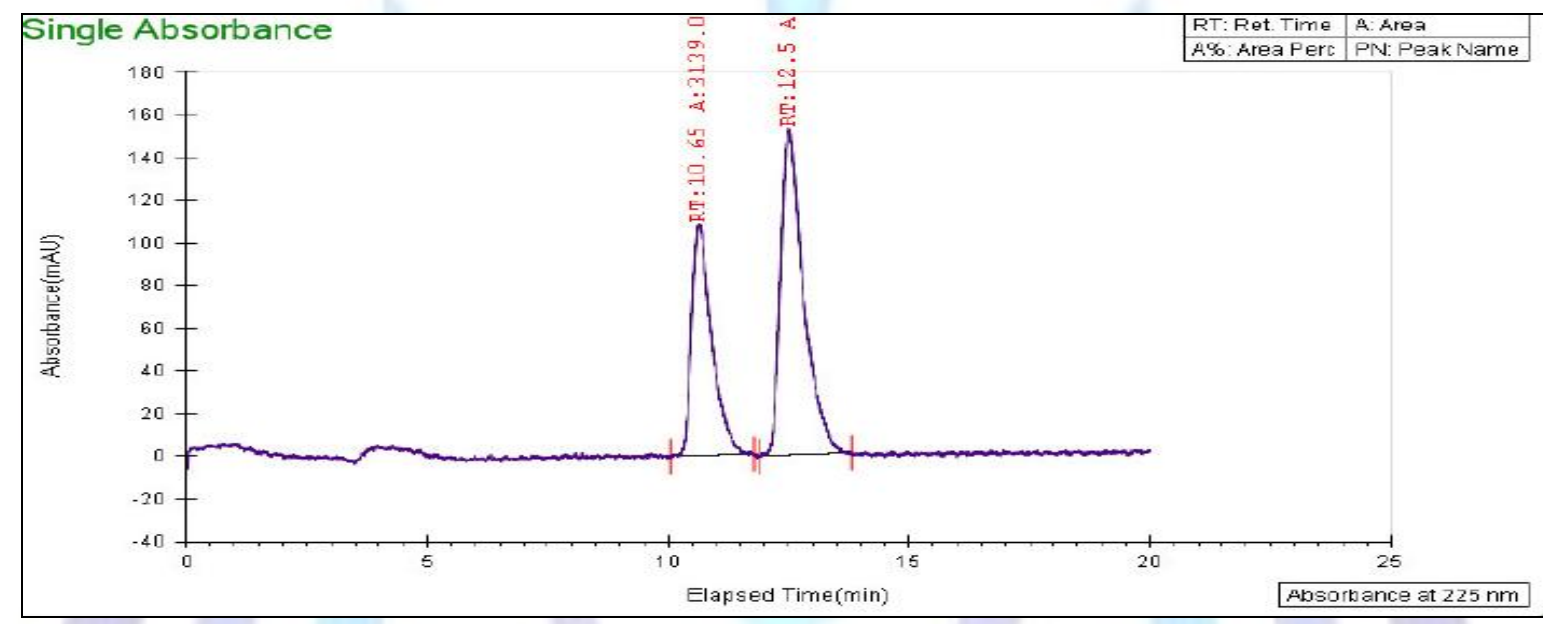

b) Montelukast s-Isomer:

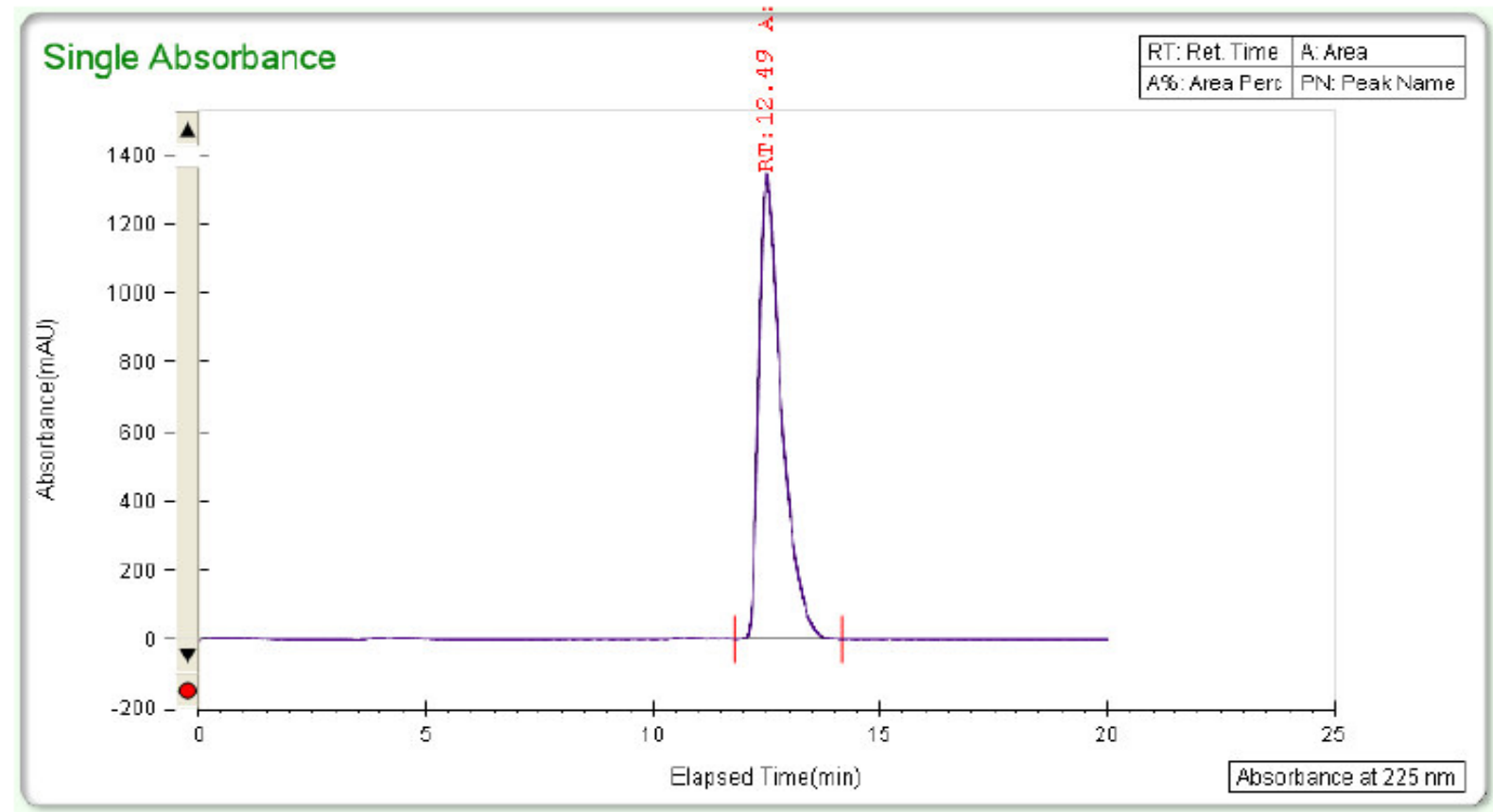


c) Montelukast sample:

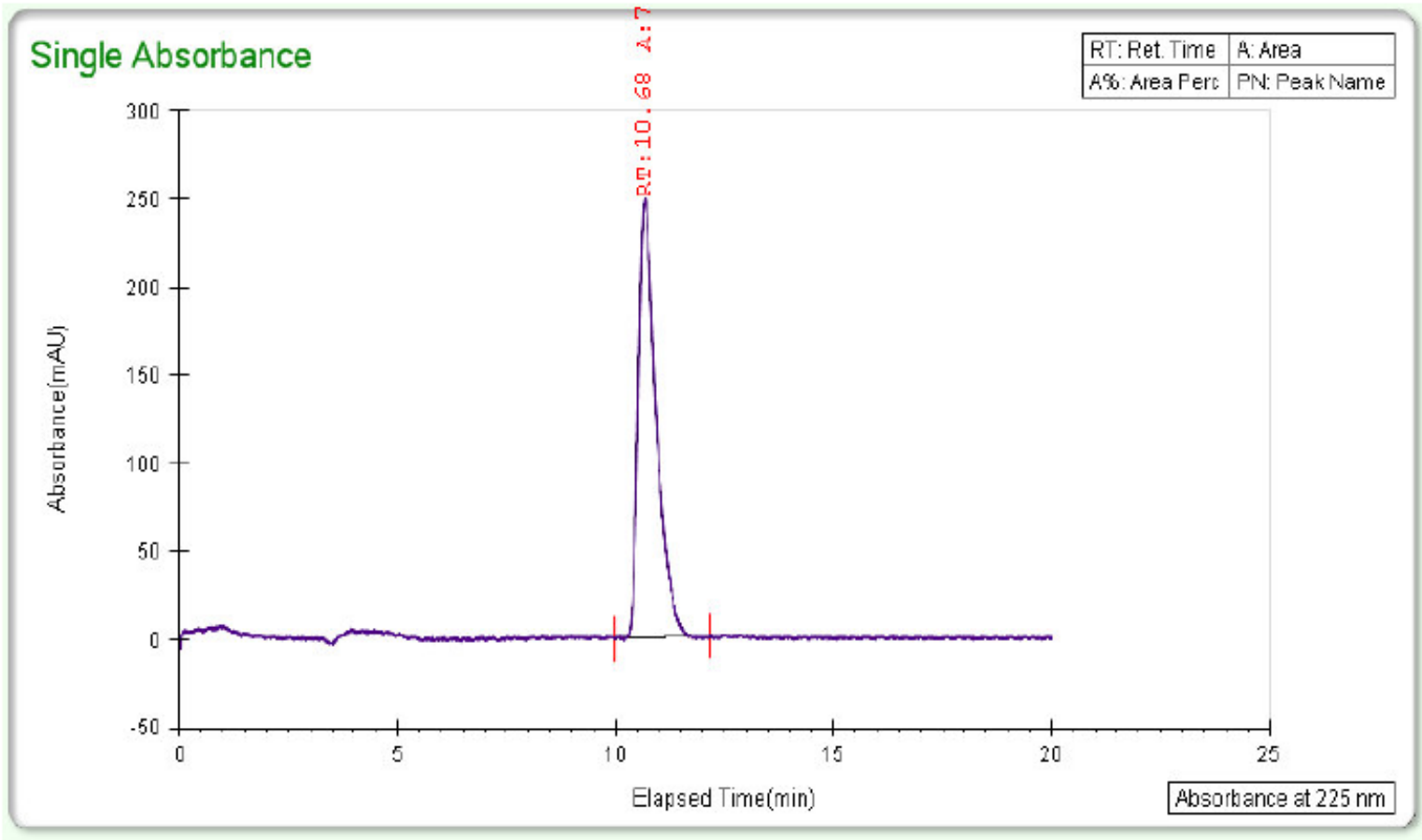

Table I. Different method development trail conditions

\begin{tabular}{|c|c|c|c|c|}
\hline S.No & Column name & Total flow $(\mathrm{g} / \mathrm{min})$ & $\%$ of Co solvent & Remarks \\
\hline 1 & Chiralcel OD-H & 2 & $15 \%$ Methanol & $\begin{array}{c}\text { No separation of } \\
\text { enantiomer }\end{array}$ \\
\hline 2 & Chiralpak IC & 2 & $15 \%($ Methanol + ACN) & Poor peak shapes \\
\hline 3 & Amylose -2 & 2 & $15 \%$ Methanol & Poor resolution \\
\hline 5 & Chiralcel OJ-H & 2 & $20 \%(0.5 \%$ TFA in ACN) & Poor resolution \\
\hline
\end{tabular}


Different Method development chromatograms for Montelukast:
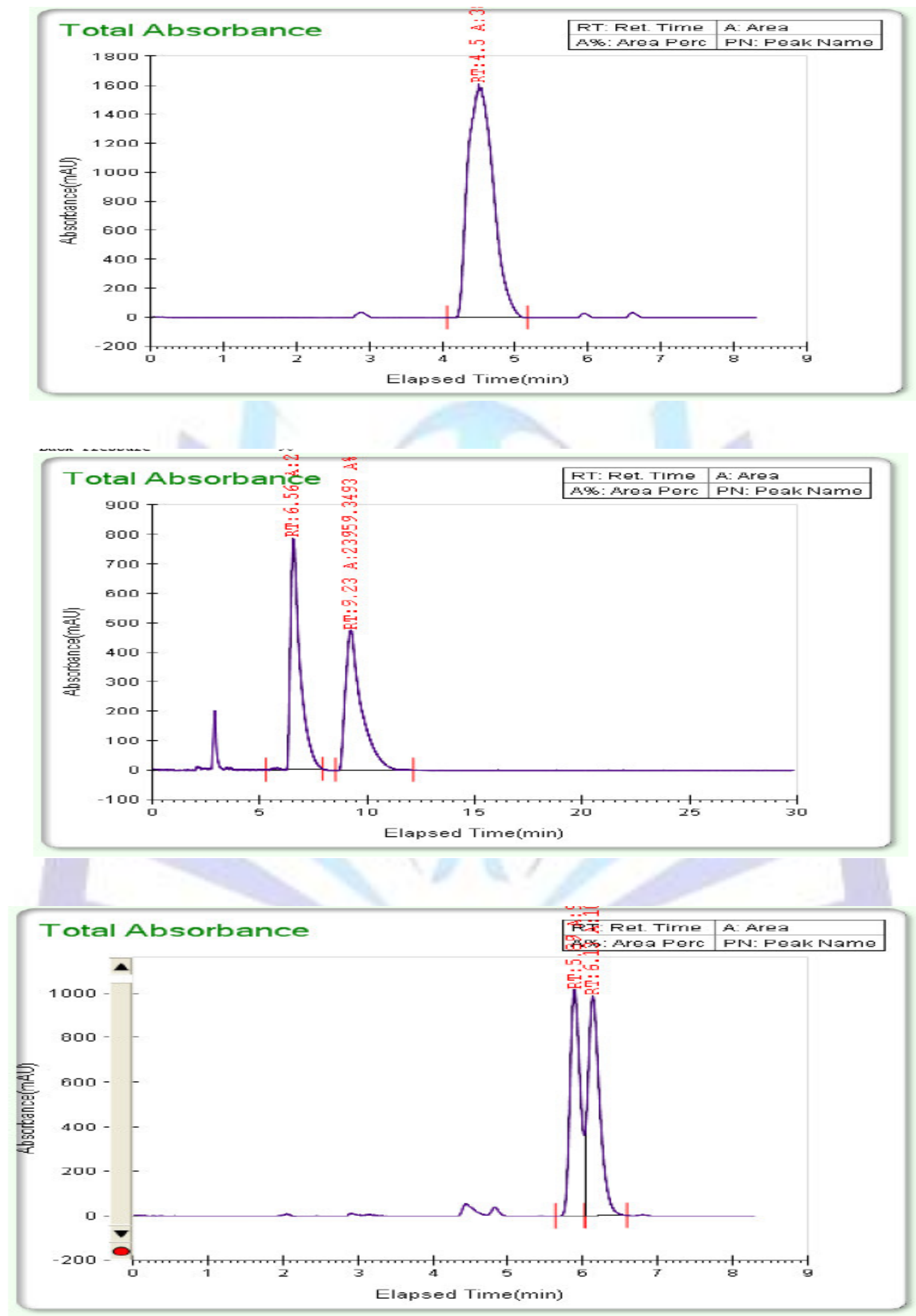
Table .II Repeatability and intermediate precision results of the developed Chiral SFC Method

\section{Parameter}

Repeatability ( $n=6, \%$ RSD)

Retention time (R-enantiomer)

Retention time (S-enantiomer)

Area (R-enantiomer)

Area (S-enantiomer)
Results

0.36

0.85

1.08

\section{References:}

1. $\mathrm{ICH}$, Validation of Analytical procedures: Text and Methodology (Q2(R1)) International conference on harmonization, IFPMA, Geneva, (2005).

2. Liu L, Cheng H, Zhao JJ, Rogers JD. Determination of montelukast (MK-0476) and S-enatiomer in human plasma by stereoselective high performance liquid chromatography with column switching. J Pharm Biomed Anal. 1997;15:631-8. [PubMed]

3. Chauhan B, Shubha Rani, Nivsarkar M, Padh H. New liquid liquid extraction method for determination for montelukast in small volume human plasma samples using HPLC with fluorescence detector. Indian J Pharm Sci. 2006;68:517-20.

4. Budavari S, editor. The Merck Index. 12th ed. Whitehouse Station, NJ: Merck \& Co Inc; 1996. p. 1070.

5. Al-Rawithi S, Al-Gazlan S, Al-Ahmadi W, Alshowaier I, Yusuf A, Raines D. Expedient liquid chromatographic method with fluorescence detection for montelukast sodium in microsamples of plasma. J Chromatogr B Biomed Sci Appl. 2001;754:527-31. [PubMed]

6. Ochiai H, Uchiyama N, Takano T, Hara K, Kamei T. Determination of montelukast sodium in human plasma by column-switching high performance liquid chromatography with fluorescence detection. J Chromatogr B Biomed Appl. 1998;713:409-14.

7. V. Choudari et al Simultaneous determination of Montelukast sodium and Levocitrazine Dihydrochloride in pharmaceutical preparations by ratio derivative spectroscopy /Int.J.PharmTech Res.2010,2(1).

8. P.Radhakrishnan and D.V.Subbarao, K.V.Surendranath,D.Subrahmanyam and V.Himabindu A validated LC method for determination of the Enantiomeric purity of Montelukast sodium in Bulk drug samples and Pharmaceutical dosage forms. Chromatographia, volume 68, Numbers 3-4(2008),263-267

9. Bhupinder singh sekhon separation of pharmaceutical enantiomers using supercritical fluid technology, International Journal of Pharmtech research Vol.2, No.2, pp1595-1602.

10. M.Sayeed Arayne, Najma sultana and Fida Hussain Spectrophotometric method for quantitative determination of Montelukast in bulk, pharmaceutical formulations and human serums, Journal of analytical chemistry volume64, Number 7(2009), 690-695. 